Review

\title{
Application of Stable Isotope-Assisted Metabolomics for Cell Metabolism Studies
}

\author{
Le You ${ }^{1}$, Baichen Zhang ${ }^{2, \dagger *}$ and Yinjie J. Tang ${ }^{1, *}$
}

1 Department of Energy, Environmental and Chemical Engineering, Washington University, St. Louis, MO 63130, USA; E-Mail: leyou@go.wustl.edu

2 Plant Metabolomics Group, Institute of Plant Physiology and Ecology, Shanghai Institute for Biological Sciences, CAS, Shanghai 20032, China

† Current address: Analytical Services, Lipospectrum LLC, 3830 Washington Blvd, Suite 121-122, St. Louis, MO 63108, USA.

* Authors to whom correspondence should be addressed; E-Mails: drbaichenzhang@gmail.com (B.Z.); yinjie.tang@seas.wustl.edu (Y.J.T.); Tel.: +1-314-629-1354 (B.Z.); +1-314-935-3441 (Y.J.T.).

Received: 13 January 2014; in revised form: 18 March 2014 / Accepted: 20 March 2014 / Published: 31 March 2014

\begin{abstract}
The applications of stable isotopes in metabolomics have facilitated the study of cell metabolisms. Stable isotope-assisted metabolomics requires: (1) properly designed tracer experiments; (2) stringent sampling and quenching protocols to minimize isotopic alternations; (3) efficient metabolite separations; (4) high resolution mass spectrometry to resolve overlapping peaks and background noises; and (5) data analysis methods and databases to decipher isotopic clusters over a broad $\mathrm{m} / \mathrm{z}$ range (mass-to-charge ratio). This paper overviews mass spectrometry based techniques for precise determination of metabolites and their isotopologues. It also discusses applications of isotopic approaches to track substrate utilization, identify unknown metabolites and their chemical formulas, measure metabolite concentrations, determine putative metabolic pathways, and investigate microbial community populations and their carbon assimilation patterns. In addition, ${ }^{13} \mathrm{C}$-metabolite fingerprinting and metabolic models can be integrated to quantify carbon fluxes (enzyme reaction rates). The fluxome, in combination with other "omics" analyses, may give systems-level insights into regulatory mechanisms underlying gene functions. More importantly, ${ }^{13} \mathrm{C}$-tracer experiments significantly improve the potential of low-resolution gas chromatography-mass spectrometry (GC-MS) for broad-scope metabolism studies. We
\end{abstract}


foresee the isotope-assisted metabolomics to be an indispensable tool in industrial biotechnology, environmental microbiology, and medical research.

Keywords: ${ }^{13}$ C-fingerprinting; flux; GC-MS; isotopologue; mass-to-charge; regulatory mechanisms

\section{Introduction}

Metabolomics measures and interprets the time-related concentration and flux of endogenous metabolites in cells [1]. Metabolomics links our physiological knowledge from genome-type to phenotype by obtaining an instantaneous snapshot of final gene products (i.e., metabolites). In metabolomics studies, extracellular metabolite profiles (metabolic footprinting or exometabolome) capture the features of overflow metabolism and offer a noninvasive approach to probe cells' physiological alterations (nutrient uptake and metabolite secretion) in the appropriate media provoked by environmental or genetic perturbations [2]. On the other hand, the profiles of intracellular metabolites reflect gene functions in complex cell metabolism. Each type of organism may have unique intracellular metabolites (metabolite fingerprints) that elucidate specific cellular processes. By comparative analyses of metabolite profiling from mutant species, metabolomics can reveal enzyme activities, silent genes, and metabolic network topology [3].

Early metabolomics relies on NMR spectroscopy, which is widely used to study pathological factors and mechanisms (e.g., xenobiotic metabolism related to drug resistance in infectious diseases or cancer chemotherapy [4]). To reveal isotopologues or calculate isotopomers, multi-dimensional NMR is required and the analysis is quite time-consuming. Alternatively, mass spectrometry (MS) based metabolite profiling also plays an important role in investigating cell metabolism. Primary metabolites (e.g., amino acids, organic acids, and sugar phosphate) can be readily identified by MS and thus have become common targets in metabolism studies [5]. Meanwhile, new analytical instruments are developed with improved chromatographic separation efficiency, linear dynamic range of ion signals, and mass resolutions. Modern MS instrument is able to probe many low abundant metabolites, particularly secondary metabolites (e.g., hormones and natural products), and may generate comprehensive insight into genome-wide cell metabolisms.

The application of metabolomics still faces several limitations due to the large percentage of noise and artifacts of MS data, which render deciphering MS data a complicated process. Firstly, the loss and degradation of metabolites during sample quenching and separation make it difficult to precisely identify and quantify unstable metabolites. Secondly, unambiguous detection of putative isobaric or isomeric metabolites is still subject to technical difficulties. Third, direct metabolite profiling cannot reveal the actual enzyme activities since a metabolite pool is regulated by its carbon fluxes (enzyme reaction rates). Lastly, the high resolution MS is expensive and inaccessible to many research laboratories. In contrast, GC-MS offers an affordable platform, but has low metabolite detection power. It is desirable to improve the potential of GC-MS to obtain more physiological knowledge from limited metabolite datasets. 
To overcome such problems, isotope tracers are introduced to track the element fates in cell metabolites and delineate functional pathways [6]. Since the 1950's, isotopes, particularly radiotracers, have been routinely applied to study enzyme reactions and are employed today to elucidate metabolic functions [7,8]. The wide application of stable isotopes $\left({ }^{13} \mathrm{C}\right.$ or $\left.{ }^{15} \mathrm{~N}\right)$ in metabolomics was realized by Dr. Fiehn and his well-established plant metabolomics group [9]. Recently, the application has been extended to GC Time-of-Flight (GC-TOF) based metabolite determination [10] and elemental formula assignments [11,12]. Meanwhile, rooted in early isotopomer analysis of metabolites with GC-MS or NMR in 1980 s, ${ }^{13} \mathrm{C}$-metabolic flux analysis $\left({ }^{13} \mathrm{C}-\mathrm{MFA}\right)$ is able to quantify in vivo enzyme functions [13-15]. Different tracer experiments (Table 1 and Figure 1), followed by isotopic analyses, allow the detection of metabolites and the quantification of intracellular metabolic fluxes in diverse organisms. More importantly, the ${ }^{13} \mathrm{C}$-fingerprinting of metabolites employs proper ${ }^{13} \mathrm{C}$-substrates to create special labeling patterns in key metabolites. By examining ${ }^{13} \mathrm{C}$-fingerprints in only a few abundant metabolites (such as amino acids), ${ }^{13} \mathrm{C}$-MFA models are able to deduce the functions of putative gene clusters and quantify global cell metabolism. For example, the biotechnology industries often use GC-MS based ${ }^{13}$ C-MFA to evaluate microbial hosts' metabolism and nutrient utilizations [6].

Stringent sampling and quenching protocols, sufficient chromatographic separations and sensitive MS analyses to reduce background noises, and proper design of tracer experiments are required to minimize isotopic alternations in isotope-assisted metabolomics. In this paper, we discuss the use of isotopes (mainly ${ }^{13} \mathrm{C}$ ) in combination with metabolomics analysis to power the metabolic investigation of primary metabolites mainly based on GC-MS in microbial systems as examples. The sample treatment, platforms for separation, and the selection of MS that are needed to precisely determine metabolites and isotopologues are discussed in details. The practical applications of isotopes for broad-scope metabolism studies are also discussed. We foresee that stable isotope-assisted metabolomics, in combination with other "omics" tools, will not only provide a complete picture of cell physiology, but also decipher regulatory mechanisms underlying gene functions.

Table 1. Summary of isotopic labeling approaches [6].

\begin{tabular}{|c|c|c|}
\hline Approaches & Description & Example \\
\hline $\begin{array}{l}\text { Isotopic dilution } \\
\text { (or enrichment) }\end{array}$ & $\begin{array}{l}\text { Grow cells with multiple carbon sources } \\
\text { (some of them are labeled); then measure labeling } \\
\text { of the metabolic products. This method is used for } \\
\text { studying cell nutrient utilizations. }\end{array}$ & $\begin{array}{l}\text { In a culture with }{ }^{13} \mathrm{C} \text {-glucose and } \\
\text { yeast extracts, analysis of } \\
{ }^{13} \mathrm{C} \text {-enrichment in proteinogenic } \\
\text { amino acids reveals the contributons } \\
\text { of yeast extract to biomass synthesis. }\end{array}$ \\
\hline Isotopic tracing & $\begin{array}{l}\text { Expose cell culture to a labeled compound } \\
\text { (pulse); then measure change of labeling in } \\
\text { downstream metabolites over time (chase). } \\
\text { Pulse-chase tracing allows isotopic } \\
\text { non-stationary MFA to quantify cell fluxomes [16]. }\end{array}$ & $\begin{array}{l}\text { The kinetics of isotopic } \\
\text { incorporation from a nutrient into a } \\
\text { downstream metabolite can detect } \\
\text { and quantify functional pathways } \\
\text { (e.g., kinetic flux profiling) [17] }\end{array}$ \\
\hline${ }^{13} \mathrm{C}$-fingerprinting & $\begin{array}{l}\text { Use specified labeled }{ }^{13} \mathrm{C} \text {-substrates to create } \\
\text { steady state and position specific labeling patterns } \\
\text { in metabolites, which delineate functional } \\
\text { pathways. }{ }^{13} \mathrm{C} \text {-fingerprint allows }{ }^{13} \mathrm{C} \text {-MFA to } \\
\text { quantify cell fluxomes. }\end{array}$ & $\begin{array}{l}\text { If cell grows with 1st position } \\
\text { labeled glucose, labeling patterns } \\
\text { in serine and alanine can examine } \\
\text { the Entner-Doudoroff } \\
\text { pathway function. }\end{array}$ \\
\hline
\end{tabular}


Figure 1. ${ }^{13} \mathrm{C}$-labeling approaches for metabolism analysis.

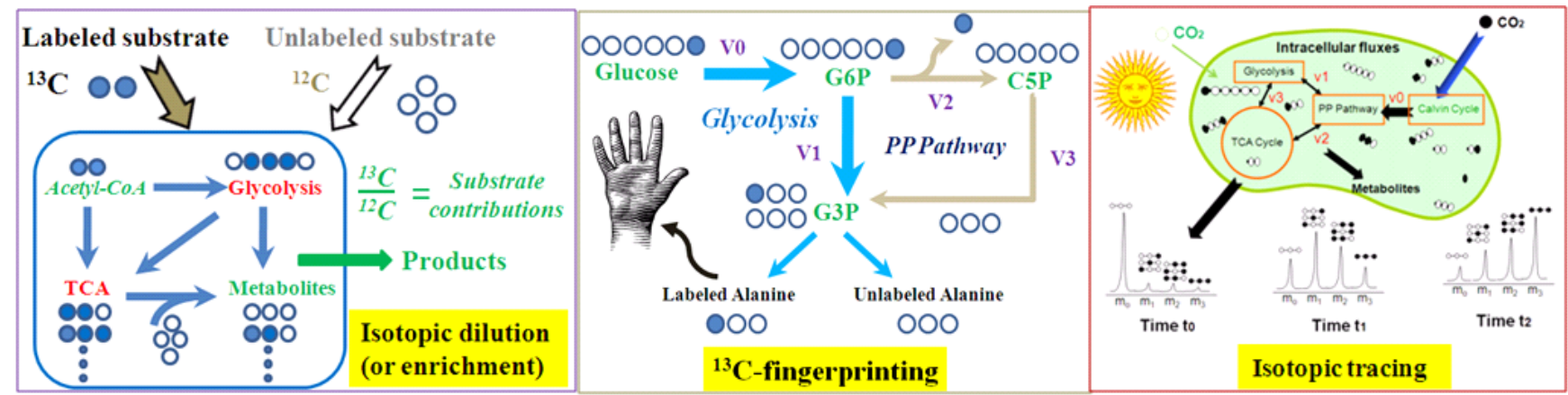

\section{Sample Preparation, Metabolite Separations, and MS Analysis}

\subsection{Metabolite Quenching}

A proper sampling procedure is critical for metabolite analysis. Rapid quenching of biological samples is often required to catch the actual metabolic snapshot since cell metabolism (especially for microbes) responds to environmental changes within seconds, and thus sample preparation may introduce artifacts in isotopic data [18,19]. Metabolite quenching can be done with fast freezing, using liquid nitrogen or perchloric or nitric acid treatments [1]. To reduce the artifacts, cold methanol $\left(-40{ }^{\circ} \mathrm{C}\right)$ is often used as a fast-quenching solution [18]. The methanol-quenched cells can be separated and lyophilized before metabolite extraction. The methanol quenching process may cause cell membrane damage [19] and drastic leakage of intracellular metabolites to the medium [20]. To minimize cell damage, cold glycerol-saline quenching solution is used [21]. Fast filtration, collecting cells by filtration under vacuum before quenching, is an alternative method to reduce metabolite loss [20,22]. To speed up this process and reduce metabolic perturbation, filter cultures were employed [23]. Cells grow on the filter paper placed on an agarose plate loaded with media and the quenching is achieved by quickly moving the filter paper from the plate to the extraction solution.

\subsection{Metabolite Extraction}

Small metabolites have to be isolated from biological samples or tissues before analyses. Metabolite extraction methods are species, agent, and technique dependent. Certain metabolite classes may need additional workups for enrichment or removal of interferences. This is particularly important for some low abundant and critical central metabolites. Interference background sometimes impairs isotopologue calculations. Even for metabolites belonging to the same class, the efficiency of different extraction methods may vary significantly. Efforts have been made to identify the optimal metabolite extraction protocols for various biological systems [19,24-26]. The five most widely used extraction methods-hot water, boiling ethanol, chloroform-methanol, freezing-thawing in methanol, and acidic acetonitrile-methanol-were tested using $S$. cerevisiae cells. In general, boiling ethanol and chloroform-methanol methods have the best performance in terms of completeness of extraction, prevention of metabolite conversion, and metabolite stability [25]. Moreover, twelve different extraction methods for mammalian cells were evaluated by extracting metabolomes of Chinese hamster ovary 
cell line [27]. The cold extraction method with 50\% aqueous acetonitrile was shown to be an optimal choice for mammalian cells.

\subsection{Metabolite Derivatization}

Chemical derivatization transforms metabolites into gaseous products to improve their detection by chromatography and MS. For GC-MS measurements, chemical derivatization increases volatility or decreases polarity of compounds that otherwise are not readily separated by GC prior to MS detection. Given the increased popularity of LC-MS systems, chemical derivatization may (1) improve the stability of unstable functional groups; (2) increase ionization efficiency and enhance detector responses of target compounds; (3) improve chromatographic separation; (4) aid in selective identification or enrichment of target analytes [28]; (5) generate characteristic MS-MS fragments of target metabolite classes to improve isotopomer determinations [29]. The chemical structure and properties of the metabolites will directly influence the derivatizing reagent choice. The most widely used derivatization reactions for GC-MS today are acylation, alkylation, and silylation [30]. The choice of derivatizing reagent is highly dependent on the structure of the functional group requiring derivatization and the selected MS technique. In ${ }^{13} \mathrm{C}$-MFA studies, two classes of silylation reagents are often used for metabolite derivatization: those generating trimethylsilyl derivatives (TMS) and those introducing tert-butyldimethylsilyl derivatives (TBDMS).

\subsection{Metabolite Separation Platforms}

The choice of the separation platforms is based on properties of metabolites of interest. GC is one of the most common technology platforms in metabolomics analysis. GC can be coupled with electron ionization (EI) sources that are less susceptible to ionization suppression. It provides accurate and low-cost measurement of sugars, amino acids, organic acids, and lipids [31]. Nonvolatile or thermally unstable metabolites (e.g., nucleotides and acyl-CoAs) cannot be directly separated by GC. Liquid chromatography (LC) is needed. Though LC peak qualities are lower than those of GC, LC separation covers a larger scope of metabolites including high molecular weight and thermally labile compounds. New technologies employing higher pressure pumps and smaller particle sizes in the LC columns lead to Ultra Performance (or Pressure) Liquid Chromatography (UPLC) with improved resolution and sensitivity, which are used to separate low abundant and unstable free metabolites. However, the conflicts among high peak capacity, LC resolution, and speed of MS detection have yet to be solved completely.

Selection of LC separation columns depends on the polarity and ionic properties of metabolites (Figure 2). HILIC (hydrophilic interaction chromatography) probes a portion of metabolomes including neutral saccharides and ionic glycan [32]. Secondary metabolites are usually moderately hydrophobic, and Reverse Phase Chromatography (e.g., RP-C18 LC column) performs best [33]. Ion Pair High Performance LC (HPLC) [34] can resolve majority of nucleotides, coenzyme A esters, sugar nucleotides, sugar bisphosphonates, and some key intermediates in secondary metabolism [35]. High pH based C18 LC column can analyze ionic and hydrophobic metabolites from both lipid metabolism [36] and secondary metabolisms (e.g., alkaloids) [37]. For separation of less ionic and hydrophobic metabolites [38,39], Reverse Phase Chromatography (RP-C18 column) with stronger 
solvent systems other than methanol and acetonitrile should be used [40-43]; HILIC or normal hydrophobic LC column may also be applicable [44]. For example, a combination of Reverse Phase Chromatography and HILIC separation improves lipidome analyses [45,46]. It should be noted that electrospray ionization MS is unable to detect hydrophobic metabolites with none or few ionizable functional groups. Atmospheric pressure chemical ionization (APCI) MS should be coupled to LC for the measurement of such metabolites (Figure 2) [47].

Figure 2. Coverage diagram of LC and CE metabolomics separation platforms.

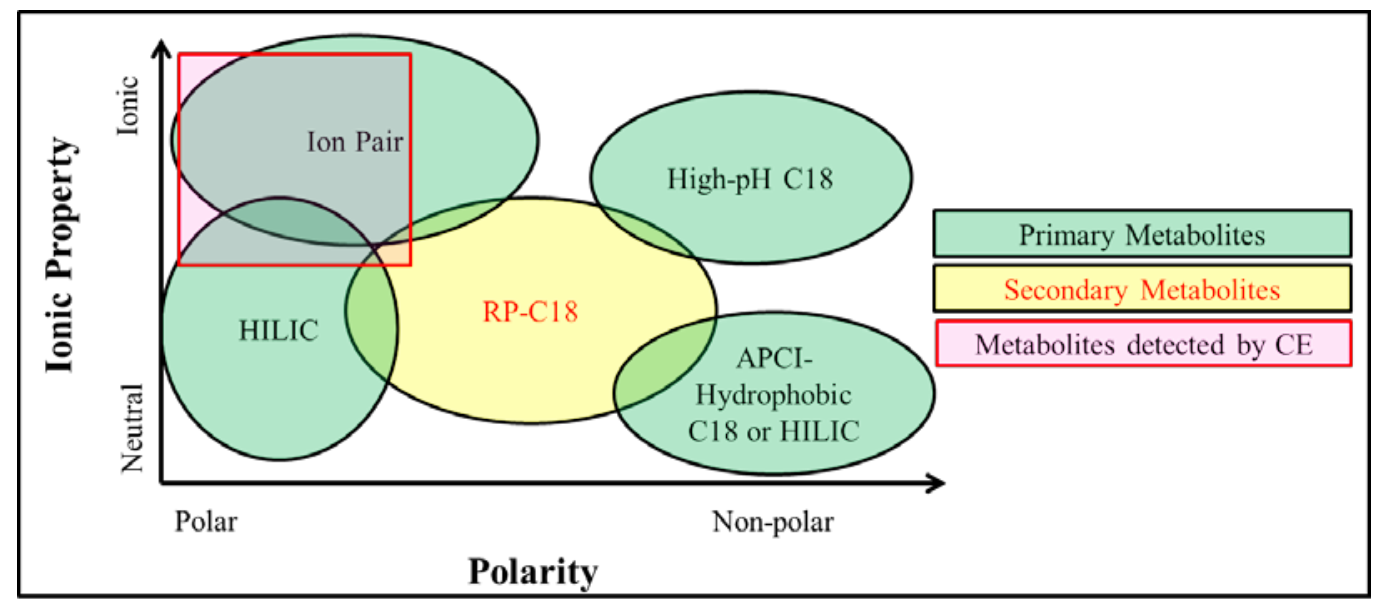

Capillary Electrophoresis (CE), a fast separation technique, separates charged species with different electrophoretic mobilities in an electric field through a conductive medium. Its separation efficiency depends on capillary length and buffer solutions. CE coupled with electrospray ionization (ESI)-MS is suitable for the analysis of highly polar and ionic compounds [48]. It should be noted that the flow rate and sample loading capacity of CE are low, and thus sensitive ESI-MS devices are essential for wide applications of CE-ESI-MS. Ion chromatography coupled with MS can be an alternative to CE-MS, and an application for measuring 16 hexose-phosphates (hexose-Ps) and nucleotide-sugars has been reported [49]. Selection of LC and CE for metabolite separation depends on system availability, affordability, and analytical targets. For example, CE-MS in combination with LC-MS has been employed to obtain profiling of ${ }^{13} \mathrm{C}$-labeling of amino acids and central metabolites in a lysine-producing Escherichia coli to reveal culture phase-dependent metabolic shifts [50].

\section{Isotopologue and Isotopomer Analysis}

\subsection{MS Resolutions}

Isotopomers are isomers with the same number of each isotopic atom but differ in position [51], whereas an isotopologue is a molecular entity that differs only in "isotopic composition" [51]. Reliable measurement of metabolites and their labeling patterns depends on MS resolution (i.e., the capability to distinguish two MS peaks of slightly different $\mathrm{m} / \mathrm{z}$ ratios). For low to medium resolution MS, metabolome analysis requires chromatographic separation. However, ultrahigh-resolution MS may perform direct infusion based methods (i.e., detection without metabolite separations) [52], leading to high throughput analyses of isotopologue profiles of amino acids [53] and nucleotides [54]. 
To understand the MS resolution for isotopologue profiling, we need to mention the trivial mass differences in isotopologue profiles for each metabolites. For ion signals of a metabolite with a general formula $\mathrm{C}_{\mathrm{x}} \mathrm{H}_{\mathrm{y}} \mathrm{O}_{\mathrm{z}} \mathrm{N}_{\mathrm{r}} \mathrm{P}_{\mathrm{s}} \mathrm{S}_{\mathrm{t}}$ [55], the formation of isotopic peaks is determined by the number of each element with natural isotopes and isotopic MS distribution [56]. Since ${ }^{13} \mathrm{C}$ comes with almost $1.1 \%$ natural abundance, it dominates the isotopic profiles among the contributions of isotopic mass from other stable isotopes, including deuterium (D), ${ }^{18} \mathrm{O}$ and ${ }^{15} \mathrm{~N}$ (note: phosphorus comes with no stable isotope). For example, in a ${ }^{13} \mathrm{C}$ experiment for a compound with chemical formula $\mathrm{C}_{8} \mathrm{H}_{10} \mathrm{NO}_{6} \mathrm{P}$, the major isotopologues will include $\mathrm{M}+0$ to $\mathrm{M}+8$ from zero to eight ${ }^{13} \mathrm{C}$ carbons. Other contributions will include $\mathrm{M}+1$ from ${ }^{15} \mathrm{~N}, \mathrm{M}+2$ from ${ }^{18} \mathrm{O}, \mathrm{M}+4$ from $2{ }^{18} \mathrm{O}$, and $\mathrm{M}+1$ from $\mathrm{D}$. All other contributions will be minor due to their lower natural abundance. Table 2 shows the exact mass differences in these isotopes. Using the combinatorial differences, we can deduce the required minimum resolution to resolve isotopologues of each metabolite.

Table 2. Major contribution to the isotopic mass difference.

\begin{tabular}{cccccc}
\hline Mass difference (in Dalton) & ${ }^{13} \mathbf{C}-{ }^{12} \mathbf{C}$ & ${ }^{15} \mathbf{N}-{ }^{14} \mathbf{N}$ & ${ }^{18} \mathbf{O}-{ }^{\mathbf{1 6}} \mathbf{O}$ & $\mathbf{D}-\mathbf{H}$ & ${ }^{34} \mathbf{S}-{ }^{32} \mathbf{S}$ \\
& $\mathbf{1 . 0 0 3 3 5 5}$ & $\mathbf{0 . 9 9 7 0 3 5}$ & $\mathbf{2 . 0 0 4 2 4 6}$ & $\mathbf{1 . 0 0 6 2 7 7}$ & $\mathbf{1 . 9 9 5 7 9 6}$ \\
\hline Mass shift & & & & & \\
M1 & 1.003355 & 0.997035 & - & 1.006277 & - \\
M2 & 2.006710 & 1.994070 & 2.004246 & 2.012554 & 1.995796 \\
M3 & 3.010065 & 2.991105 & - & 3.018831 & - \\
M4 & 4.013419 & 3.988140 & 4.008492 & 4.025108 & 7.983184 \\
\hline
\end{tabular}

Note: each column indicates the exact mass shifts with the increase of the numbers of isotopes.

According to previous report, mass resolution calculation is based on the closest distinguishable separation between two MS peaks of equal height and width, which is a function of $\mathrm{m} / \mathrm{z}$, mass peak width, and the relative mass abundant ratios of two mixed isotopologue peaks [57]. A convenient equation below can estimate the minimum resolutions for MS analysis. For a rigorous measurement, the Constant can be assumed as ten [57].

$$
\text { Minimum Resolution }=\frac{\text { Monoisotopic Mass }}{\text { Mass Difference between Closest Isotopologues }} \times \text { Constant }
$$

If the Constant in Equation (1) is set as three (assuming a less rigorous MS measurement), we plot the minimum resolutions required for isotopologue analysis of hypothetical metabolites (Figure 3). As an example, the dot beside the red arrow in Figure 3A represents metabolite fragments with $\mathrm{m} / \mathrm{z}$ of 100 , which may contain one ${ }^{34} \mathrm{~S}$ or two molecules of ${ }^{13} \mathrm{C}$. To differentiate between the $\mathrm{M}+2$ results from either one ${ }^{34} \mathrm{~S}$ or from the two ${ }^{13} \mathrm{C}$, a minimal resolution can be calculated as $\frac{100}{2.006710-1.995796} \times 3=27488$ (see Table 2). Thereby, we have one dot at the $x-y$ coordinates (100, 27,488) in Figure 3A. In a similar approach, the cloud of dots in Figure 3A represents the resolutions required to distinguish major isotopologues for metabolites of different $\mathrm{m} / \mathrm{z}$. Figure $3 \mathrm{~B}$ reports the minimum resolutions required to analyze isotopologues from a mixture of amino acids (121 data points). Figure 3C (4,598 data points) represents the minimum resolutions required to resolve two isobaric metabolites (metabolites with the same molecular weight) in a mixture of hypothetical 
metabolites without considering effects due to isotopologues (or isotopic peaks). Similar to Figure 3B, Figure 3D reports the minimum resolution required to resolve close isotopologues $(160,253$ data points) in a mixture of hypothetical metabolites.

Figure 3. Resolutions required for metabolomics analysis [57]. Panel (A) shows the resolutions required to distinguish major isotopologues for metabolites of different $\mathrm{m} / \mathrm{z}$. Panel (B) shows the resolution required to resolve major isotopologues in amino acid mixture. Panel (C) shows resolution required to resolving isobaric masses in hypothetical metabolite mixture without considering isotopologues or isotopic peaks. Panel (D) shows resolution required to resolve common isotopologues of hypothetical metabolite mixture.

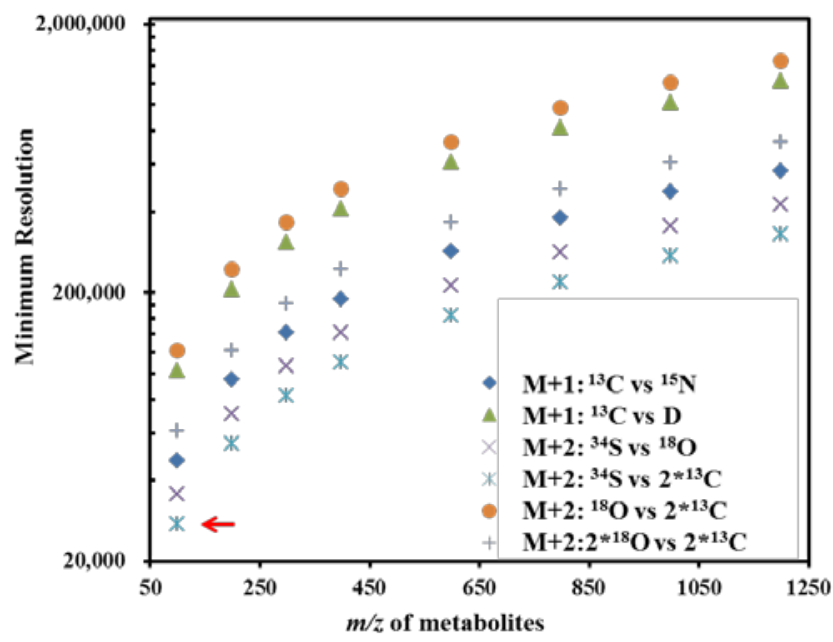

(A)

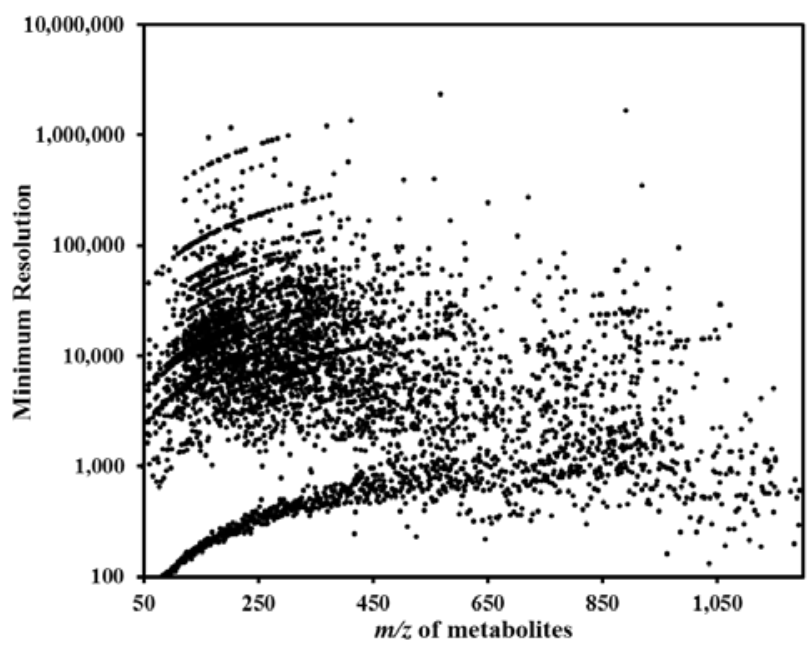

(C)

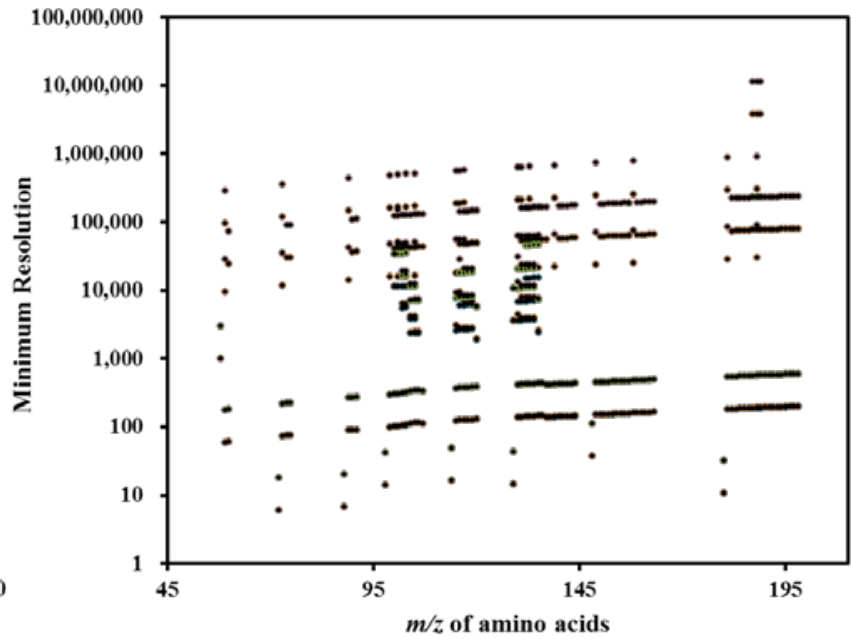

(B)

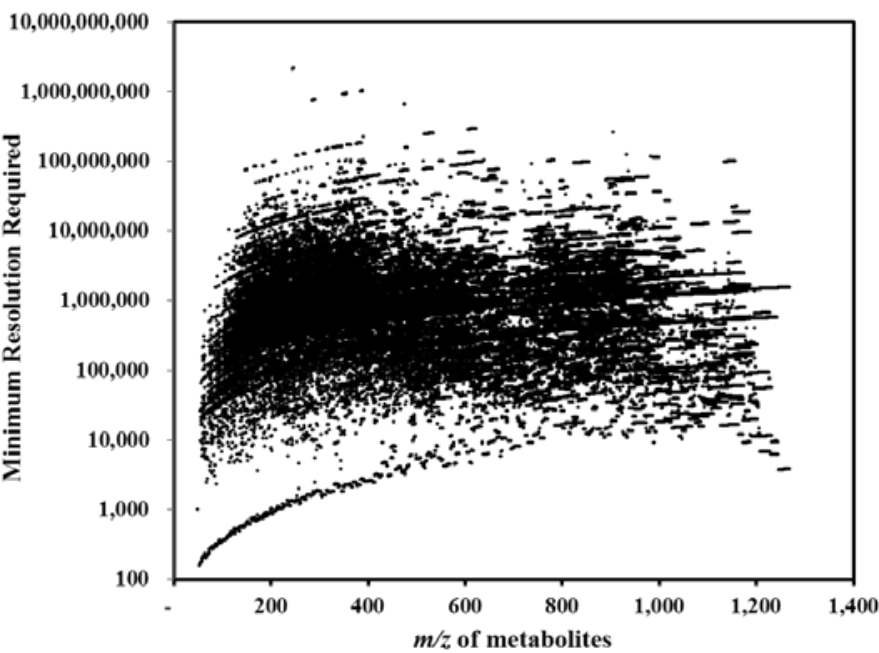

(D)

For metabolites with mass below $300 \mathrm{~m} / \mathrm{z}$, Orbitrap, QExactive Plus, and FT-ICR platform can reach the capacity to resolve the isotopologues of individual metabolites provided no overlapping signals from other metabolites or background ions. However, when the $\mathrm{m} / \mathrm{z}$ increases to $800-1,200 \mathrm{~m} / \mathrm{z}$ (in the range of lipid metabolites), a resolution over 400,000 is required, a feat still hard to realize with most available high resolution MS. The simulated requirement of resolution for amino acid mixture is provided in Figure 3B. Despite the past successes of resolving or partially resolving the isotopologues of a mixture of common amino acids, such as those from protein lysates, the requirement of resolution 
is still well beyond the reach of the majority of TOF (Time of flight) instruments, which has a maximum resolution between 20,000 and 100,000. Therefore, though the complete resolving of isotopologues in metabolite mixtures without separation is ideal, the required resolution renders it impossible to fulfill this goal with any MS that has been proposed to date (Figure 3C,D).

\subsection{MS Platform Selection}

MS platforms for metabolomics studies should be chosen based on research purposes and affordability. Medium to low resolution MS, such as traditional GC-MS, Triple-Quadruple instruments and some TOF instruments, Q-Exactive or Orbitrap may analyze isotopologue profiles in the aid of chromatographic separation. The GC-MS is particularly good for studies on central metabolism by measuring amino and organic acids using automated standard library searches. A system evaluation of GC-MS, LC-TOFMS and LC-MS-MS has indicates that low-cost GC-MS with an electron ionization source still provides satisfactory isotopologue analysis of many metabolites and the GC-MS datasets can be directly implemented in fluxomics software [58].

Metabolimcs sciences are continously growing and new MS tools are rapidly developed for metabolite identification and quantification [59]. Ultra-high resolution instruments, such as FT-ICR-MS, can perform direct infusion MS (DI-MS) to probe organic acids and carbohydrates from biological samples [52]. However, due to isobaric interference and a large number of isomers, many ions shown in DI-MS cannot be differentiated. For example, over $57 \%$ of metabolites from a summary of 7,876 compounds (MW between 50 and 1,200) recorded in MetaCyc [60] and PlantCyc databases have isomeric counterparts [61]. In an extreme case, there are 40 isomers recorded for the commonly occurring hexoses with a formula $\mathrm{C}_{6} \mathrm{H}_{12} \mathrm{O}_{6}$. No report to date has addressed the challenges of resolving all of isotopomers in one assay. As a consequence, chromatographic separation of metabolite mixture will still dominate future ${ }^{13} \mathrm{C}$ - metabolomics.

MS-MS-based platform is a powerful metabolomics tool. High resolution full scan spectra can perform putative identifications of metabolites, and the subsequent MS (MS ${ }^{2}$ ) is used to confirm molecular structure. To obtain the high-quality $\mathrm{MS}^{2}$ data and remove unreliable fragments due to instrument noise and high complex sample compositions, a two-part approach for performing metabolomic identifications has been proposed, and a data analysis package (decoMs ${ }^{2}$ ) implementing the algorithms in the workflow can obtain deconvolved $\mathrm{MS}^{2}$ spectra for many biological compounds [62]. Alternatively, the high-resolution UPLC-TOFMS ${ }^{\mathrm{E}}$ (E represents collision energy) in combination with mass defect filtering can identify both expected and unexpected metabolites from a single LC/MS acquisition [63].

\section{Data Analysis}

Processing ${ }^{13} \mathrm{C}$-metabolomics data to obtain the isotope enrichment or the position of the isotope in the molecules depends on MS systems and the tracer experiment design. There is no universal software tool available for this purpose. When a single isotope label is used, it is not necessary to require resolving various isotopologues from different natural isotopes. Instead, it is common practice to use low resolution MS instruments. In this case, isotopologues originating from various abundant natural isotopes (such as ${ }^{13} \mathrm{C},{ }^{15} \mathrm{~N},{ }^{18} \mathrm{O}$ et al.) are convoluted in isotopic clusters. Enriched isotopic abundance can be deducted after removing the natural isotopic abundance by mathematical algorithms [64]. 
For isotopomer analysis, MS fragments are necessary. Even for isotopomers from a single type of isotopes, such as carbon, the possible number of isotopomers $\left(2^{\mathrm{n}}: \mathrm{n}\right.$ represents number of elements in a chemical formula) can be quite large. Therefore, the complete calculation of isotopomers is possible only when $\mathrm{n}$ is small and enough MS fragments are available with fair abundance.

Usually MS-MS spectra need to be extracted for subsequent correction of natural isotopic abundance [65]. For LC-MS-MS with low resolution MS instruments such as Qtrap, an exhaustive MRM (multiple reaction monitoring) list can compute possible isotopomers if enough MS-MS fragments are detectable [66]. Recent versions of commercial triple quadruple MS may allow over 3,000-4,000 MRMs programmed and will be beneficial to this type of experiment. However, MS analysis may not distinguish isotopologues if multiple isotopes are present in the sample [67]. Moreover, the convolution of isotopologues, isobaric overlapping, and background interference in MS measurement may dramatically decrease its sensitivity to detect small percentage of isotopic enrichment. ESI noises are notoriously difficult to control. For ultra-high resolution MS, preemptively correcting natural isotopic abundance can avoid convolution of isotopologues [68]. However, it is problematic when the instrument can only partially resolve the isotopologues. Partially separated isotopologues may complicate the peak extraction algorithms, mass accuracy, and isotopic correction. The situation is more complex if structurally uncharacterized metabolites are present in the samples, which are common in metabolomics experiments. Academic agreement has yet to be reached on how labeled metabolomics data from poorly characterized metabolites should be presented.

Many MS vendors provide data analysis tools for metabolomics. There are several options for analyzing the large datasets from metabolomics experiments [61,69]. (1) Vendor supplied software, such as ChromaTOF (LECO Pegasus GC-TOF, Saint Joseph, USA) software, MassHunter (Agilent TOF systems, Santa Clara, USA), Orbitrap (Thermo Fisher Scientific, Waltham, USA), and Sieve (QExactive, City, Country); (2) Third-party software is also available. For example, Non-linear Dynamics released Progenesis CoMet for analyzing LC-MS data; (3) Database and profiling software released from academic laboratories, such as XCMS [70], mzMine [71,72], and the METLIN Metabolomics Database [73]. However, commercial software does not meet the requirements to analyze isotopically enriched metabolomics data. Unresolved isotopologues from high resolution MS may block automated data processing. Automated MS/MS fragment interpretation is even more challenging. Reliable peak extraction is convoluted by partially resolved isotopologues and overlapped metabolites. Background MS noises add additional complexity. Current chromatography cannot completely resolve overlapped metabolites. Therefore, reliable data analysis methodologies for isotopically labeled metabolomics datasets are still under further development and require additional efforts from individual research laboratories as well as collaborations from commercial vendors, third party software suppliers, and an open source community. A uniformed algorithm collection or workflow with options flexible for instrument systems is advantageous. More importantly, a blueprint for validating various data analysis algorithms will help the researchers to pick the right software to analyze the labeled metabolomics dataset and avoid pitfalls for data analysis. 


\section{Application of Isotope-Assisted Metabolomics}

\subsection{Isotope Analysis for Tracking Nutrient Utilizations}

A rich medium contains bottleneck nutrients to promote cell growth and product synthesis. When a ${ }^{13} \mathrm{C}$-labeled substrate is supplied in rich mediums, the metabolites synthesized de novo from the substrate will be labeled, while metabolites derived from the undefined nutrients in the medium are not (Figure 1). Therefore, ${ }^{13} \mathrm{C}$-labeling in biogenic and exogenous metabolites can identify the essential nutrients that are not effectively synthesized from primary substrates [74]. This method has particular value in medical research for disease diagnoses and pathological analysis. This method has also been used to identify the bottleneck nutrients for alkaline protease synthesis in an industrial microbial host [75]. In another example, the favorable nutrients for a slow growing Dehalococcoides ethenogenes (doubling times $\sim 2$ days) were investigated. ${ }^{13} \mathrm{C}$-dilution of proteinogenic amino acids using uniformly labeled acetate in a rich medium identified that only four amino acids are useful for promoting Dehalococcoides growth [76]. Moreover, ${ }^{13} \mathrm{C}$-labeling can also reveal the co-metabolism of multiple carbon substrates [77] as well as photomixotrophic biosynthesis processes [78].

\subsection{Isotope-Assisted Metabolite Identifications}

Isobars (molecules with same mass but different chemical compositions) may have trivial mass differences. However, their elemental composition may differ significantly. In terms of biogenesis, isobars originate from completely different metabolic pathways. By dosing specific labeled precursors, isobars can be resolved due to differences in isotopic enrichment. It is particularly self-evident when one isobar does not undergo isotopic incorporation and another does. Thereby, isotope labeling can help the unambiguous identification of metabolites. Differentiation of isobaric compounds or isomers (molecules having the same chemical composition but different chemical structures) requires sophisticated MS techniques to manipulate electric fields and design chemical ionization reactions to provide analytical selectivity $[79,80]$. Since labeled isotopes are distinguishable from abundant natural isotopes by $\mathrm{m} / \mathrm{z}$ ratios, ${ }^{13} \mathrm{C}$ and ${ }^{15} \mathrm{~N}$ labeling of biological samples often assist metabolite analysis [81]. By comparing exact MS data from metabolites resulting from different combinations of $\mathrm{C}$ and $\mathrm{N}$ tracers, high-confident metabolite identifications of isobaric compounds with different elemental compositions can be easily achieved [79-86]. For example, using a combination of ${ }^{13} \mathrm{C}$ and ${ }^{15} \mathrm{~N}$, untargeted metabolite profiling has identified cyanobacterial metabolites that are not annotated by its genome databases [83]. Besides, ${ }^{13} \mathrm{C}$ and ${ }^{15} \mathrm{~N}$ labeling has also been used to differentiate or identify the metabolites from contaminants (i.e., compounds of non-biogenic origin). For example, ${ }^{13} \mathrm{C}$-labeling and FT-ICR MS analysis have detected phytoplankton metabolic footprints in the seawater and improve our understanding of the role of exuded compounds from phytoplankton in an ecological system [84].

\subsection{Isotope-Assisted Metabolite Quantification}

Enzymatic and chromatographic methods cannot precisely measure concentrations of low abundant intracellular metabolites. To overcome this problem, the use of isotopically labeled metabolites as internal standards can assist MS analysis to determine metabolite concentrations under the noise of 
sample degradation and instrumental variations [87]. Since standards of ${ }^{13} \mathrm{C}$-metabolites are expensive, the isotope dilution technique applies a modified inverse labeling approach [23]. With this approach, cells are grown in fully labeled substrates to yield exclusively labeled intracellular metabolites. Then, unlabeled internal standards in known concentrations can be mixed with the labeled cell samples during metabolite extraction. MS analysis of isotopologue data can obtain the ratio of endogenous metabolites to internal standards from the co-extracted sample. Absolute metabolite concentrations on the basis of standard concentrations can then be calculated [23]. This approach has been extended to determine metabolite turnover rates [17]: after cell cultures undergo a step change from unlabeled to ${ }^{13} \mathrm{C}$-labeled nutrient, the rate of ${ }^{13} \mathrm{C}$ enrichments in a metabolite multiplied by its pool size gives the metabolite turnover rate (i.e., flux). Such kinetic flux profiling can probe pathway responses to diverse growth conditions [88] and discover the functions of enzymes in pathogens [89].

\subsection{Isotope-Assisted Pathway Investigations}

${ }^{13} \mathrm{C}$-tracer experiments are widely used to confirm or discover functional pathways [6]. For example, a threonine-independent route for isoleucine synthesis was found in a cyanobacterium by using $2-{ }^{13} \mathrm{C}$ glycerol to fingerprint its metabolites [66]. Based on labeling features for threonine, isoleucine, and leucine, a citramalate pathway was discovered as an alternate isoleucine synthesis pathway in this strain. Moreover, the ethylmalonyl-CoA pathway in Methylobacterium extorquens was discovered by monitoring label-incorporation from $1-{ }^{13} \mathrm{C}$ acetate into the pathway intermediates over time [90]. In the metabolic engineering field, ${ }^{13} \mathrm{C}$-labeling can determine the contribution of a certain pathway in the synthesis of a product and confirm the engineered pathway functions. For example, a recent study infers that ${ }^{13} \mathrm{C}$-labeling may examine a non-oxidative glycolytic cycle in $E$. coli that breaks down glucose into acetyl-CoA without carbon loss [91]. Besides pathway investigation, ${ }^{13} \mathrm{C}$ tracer experiments can determine the physiological role of a functional enzyme by detecting the ${ }^{13} \mathrm{C}$ profile in a corresponding mutant [77]. The role of malic enzyme for pyruvate synthesis in S. cerevisiae was determined by tracking the labeling patterns of pyruvate in the isogenic strain when the malic enzyme was deleted [77]. In addition, the understanding of metabolic pathways and their regulations is important in biology and biomedical fields [92-96]. For example, cancer cells have different metabolic characteristics, such as fast cellular proliferation, increased local invasion, and metastases from their normal counterparts $[97,98] .{ }^{13} \mathrm{C}$ isotopic labeling can identify the metabolic pathway changes in the central metabolism that lead to the altered metabolic phenotypes in cancer cells [99-102]. Such analysis can reveal promising targets for future cancer therapies [103].

Stable isotope tracing has also been used for elucidation of network-wide metabolic pathways. For example, to analyze the glutamine metabolism in A549 human lung carcinoma cells, in which a compound library was first obtained using unlabeled cultures [85]. Then the labeled tracer (U- ${ }^{13} \mathrm{C}$ glutamine or amine-labeled $\alpha-{ }^{15} \mathrm{~N}$ glutamine) was supplied to cell culture with unlabeled glucose to fingerprint downstream metabolites. The mass isotopomer distributions of broad-scope metabolites provide critical confirmation of carbon fluxes percolated through the metabolic network. Such untargeted tracer fate detection offers great potential to study biochemical reactions that are currently unknown. The high-resolution MS and the advances in genome databases have greatly improved the extent of untargeted analyses of network-wide pathways [86]. 


\section{5. ${ }^{13}$ C-assisted Metabolic Flux Analysis}

Metabolic responses to genetic or environmental modifications can be monitored based on the steady state ${ }^{13} \mathrm{C}$-MFA [104-106], which often quantify fluxes based on ${ }^{13} \mathrm{C}$-fingerprints in proteinogenic amino acids [105]. ${ }^{13} \mathrm{C}-\mathrm{MFA}$ can also reveal algal mixotrophic metabolism using both $\mathrm{CO}_{2}$ and organic carbon substrates [107]. However, steady state ${ }^{13} \mathrm{C}-\mathrm{MFA}$ is not able to reveal the photoautotrophic metabolism or the dynamic metabolic responses. The advances in LC-MS techniques facilitate the development of isotopic non-stationary MFA (INST MFA) by capturing isotopomer dynamics of fast turnover intracellular metabolites [16,108]. Nowadays, INST MFA can analyze not only microbes, but also plant and mammalian cells [109]. In the biotechnology industry, non-stationary ${ }^{13} \mathrm{C}$-metabolic flux ratio analyses via isotopic tracing have obtained the snapshots of the metabolic fluxes through several key nodes in B. subtilis [108]. Time-dependent fluxomics has also been proposed to investigate $B$. subtilis fermentation processes [110].

${ }^{13} \mathrm{C}$-MFA models for mammalian and plant cells are much more complex than bacterial models in several ways. Firstly, the subcellular compartments of mammalian cells are highly active in carbon and energy transportation. The measurement of compartmented metabolites is difficult due to their small pool size and high leakage [111]. Secondly, during eukaryotic cell cultivation, it is difficult to ensure metabolic steady-state conditions for metabolic flux analysis [112]. Thirdly, complex media, essential for mammalian cell growth, includes undefined nutrition that encumbers metabolic flux calculations. Fourthly, the analysis of plant autotrophic metabolism requires INST MFA [16], and involves costly LC-MS analysis of low abundant and unstable free metabolites. Lastly, metabolite channeling and compartmentation may occur in eukaryote cells, which pass intermediates from enzyme to enzyme without reaching cellular medium equilibration. This alters the isotopomer composition of downstream metabolites [113] and creates high noises for flux estimation. Nevertheless, extensive efforts have been made to determine the metabolic functions in plant and mammalian cells via isotopic labeling [114-116], in which Chinese hamster ovary (CHO) cells are most well studied using flux analysis approaches [117-119].

\section{6. ${ }^{13}$ C-asssited Metabolic Analysis of Microbial Communities}

Species in microbial communities has complex nutrient interactions [120,121]. In ecology, stable isotope is widely used to determine microbial community populations and carbon assimilation patterns. For example, after feeding ${ }^{13} \mathrm{C}$-toluene to a microbial consortium, toluene-degrading microorganisms were identified by analyzing ${ }^{13} \mathrm{C}$-fatty acids (via GC-combustion-isotope ratio $\mathrm{MS}$ ) and sequencing ${ }^{13} \mathrm{C}$-labeled 16S rRNA [122]. Moreover, ${ }^{13} \mathrm{C}$ or ${ }^{14} \mathrm{C}$-approaches have been used to examine the metabolic interactions between microbial pathogens and their hosts [123]. For example, ${ }^{13} \mathrm{C}$-labeling can study the pathways used by intracellular pathogens or their mutants to determine nutrient utilization during infection [124,125]. Currently, actual metabolisms among community species are still difficult to investigate. It is difficult to obtain metabolites from a given species within a mixed culture because it requires complete separation of this species by repeated centrifugations or fluorescence-assisted cell sorting. To overcome this problem, a proof-of-concept for metabolite isolation from a community system has been proposed [126]: a "reporter protein" that has been synthesized in only one species of 
the consortium can be separated via chromatographic protein purification. Then ${ }^{13} \mathrm{C}$ patterns of proteinogenic amino acids from the reporter protein can be used in isotopic fingerprinting.

\section{Future Directions and Conclusions}

Isotope labeling has played an important role in studies regarding functional characterization of the cell genome and provided insights into cell physiologies. However, there are still many areas of cell metabolisms and their multiple level regulations are unknown. Systems profiling of messenger RNAs, proteins, and metabolites have been shown to offer a comprehensive insights into the intracellular activities and their regulatory network [127]. Recently, transcriptomics, proteomics, and metabolomics are extensively used to obtain a systematic insight into the multiple cellular processes and genetic regulations [128-131], where the metabolomics is the key to link multiple omics data for functional genomics studies [132]. Due to the putative post-transcription regulation, the correlation among genomics, transcriptomics, and metabolomics data is still not straightforward. For some genes, increases in mRNA levels may not lead to the increase in protein levels; for other genes, the mRNA levels are the same value but the protein levels vary significantly [133]. Moreover, the existence of isoenzyme and poor enzyme specificity contribute to high metabolome diversity ("too few genes, too many metabolites” [134]), which hinders the linkage between genomics and metabolomics. Therefore, the integration and application of multiple omics data sets is still in its preliminary phases and requires iterative "omics” analysis and experimental verification (Figure 4).

Figure 4. Metabolic knowledge mining by constructing an iterative method to interpret multiple omics data sets.

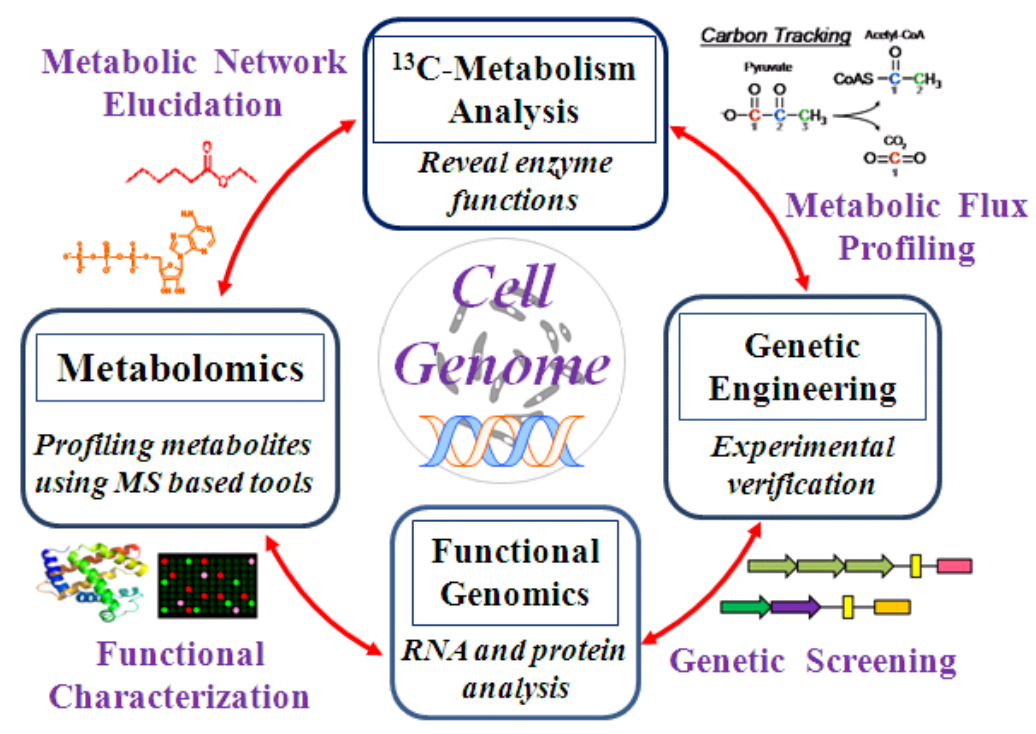

Isotope-assisted metabolomics is undergoing four technique developments. First, rapid MS detection without a separation stage can speed up screening of large biological samples, but it is only applicable for certain classes of metabolites or simplified metabolite mixtures. This is seen in nanostructure-initiator mass spectrometry (NIMS)-based approaches for screening targeted metabolic compounds and provides an important tool in characterization of enzymes from environmental microbes $[135,136]$. Second, MS analysis must include extensive efforts to generate information-rich 
MS-MS fragments with collision-induced dissociations in order to completely resolve isotopomer distributions. Otherwise, NMR techniques have to be applied for assisting MS for molecule structure analysis $[137,138]$. To overcome the challenges for separation and identification of isobars, UPLC and ultra-high resolutions MS are proposed to separate and detect very small mass differences among isomers [139]. Third, multiple isotopic labels $\left({ }^{2} \mathrm{H},{ }^{13} \mathrm{C}\right.$, and ${ }^{18} \mathrm{O}$ tracers) can be used simultaneously to obtain maximum metabolic information in complicated networks. Fourth, by knowing only a few isotopologues in key metabolites, isotopomer tracing models (i.e., algorithms used in ${ }^{13} \mathrm{C}-\mathrm{MFA}$ ) may deduce the complete isotopomer compositions resulting from labeled substrates [140]. Above-mentioned developments will ultimately expand the horizon of isotope-assisted metabolomics research, which measure and interpret the time-related metabolite concentrations and enzyme activities in an unprecedented manner.

\section{Acknowledgments}

We thank Xuechuan Hong from Wuhan University for useful comments. We also thank Katrina Leyden for editing the paper. Our research was funded by an NSF Career Grant (MCB0954016). Baichen Zhang would like to acknowledge the generous startup funding from Chinese Academy of Sciences for his research group.

\section{Author Contributions}

Le You and Yinjie Tang wrote Sections 1, 5, 6. Le You, Baichen Zhang and Yinjie Tang wrote Section 2. Baichen Zhang wrote Sections 3 and 4. All authors revised the paper.

\section{Conflicts of Interest}

The authors declare no conflict of interest.

\section{References}

1. Fiehn, O. Metabolomics - The link between genotypes and phenotypes. Plant Mol. Biol. 2002, 48, 155-171.

2. Allen, J.; Davey, H.M.; Broadhurst, D.; Heald, J.K.; Rowland, J.J.; Oliver, S.G.; Kell, D.B. High-throughput classification of yeast mutants for functional genomics using metabolic footprinting. Nat. Biotechnol. 2003, 21, 692-696.

3. Raamsdonk, L.M.; Teusink, B.; Broadhurst, D.; Zhang, N.; Hayes, A.; Walsh, M.C.; Berden, J.A.; Brindle, K.M.; Kell, D.B.; Rowland, J.J.; et al. A functional genomics strategy that uses metabolome data to reveal the phenotype of silent mutations. Nat. Biotechnol. 2001, 19, 45-50.

4. Griffin, J.L. Metabonomics: NMR spectroscopy and pattern recognition analysis of body fluids and tissues for characterisation of xenobiotic toxicity and disease diagnosis. Curr. Opin. Chem. Biol. 2003, 7, 648-654.

5. Kind, T.; Wohlgemuth, G.; Lee do, Y.; Lu, Y.; Palazoglu, M.; Shahbaz, S.; Fiehn, O. FiehnLib: Mass spectral and retention index libraries for metabolomics based on quadrupole and time-of-flight gas chromatography/mass spectrometry. Anal. Chem. 2009, 81, 10038-10048. 
6. Tang, J.K.-H.; You, L.; Blankenship, R.E.; Tang, Y.J. Recent advances in mapping environmental microbial metabolisms through ${ }^{13} \mathrm{C}$ isotopic fingerprints. J. R. Soc. Interface 2012, 9, 2767-2780.

7. Tjellstrom, H.; Yang, Z.; Allen, D.K.; Ohlrogge, J.B. Rapid kinetic labeling of Arabidopsis cell suspension cultures: Implications for models of lipid export from plastids. Plant Physiol. 2012, 158, 601-611.

8. Bates, P.D.; Ohlrogge, J.B.; Pollard, M. Incorporation of newly synthesized fatty acids into cytosolic glycerolipids in pea leaves occurs via acyl editing. J. Biol. Chem. 2007, 282, 31206-31216.

9. Fiehn, O. Combining genomics, metabolome analysis, and biochemical modelling to understand metabolic networks. Comp. Funct. Genomics 2001, 2, 155-168.

10. Huege, J.; Sulpice, R.; Gibon, Y.; Lisec, J.; Koehl, K.; Kopka, J. GC-EI-TOF-MS analysis of in vivo carbon-partitioning into soluble metabolite pools of higher plants by monitoring isotope dilution after ${ }^{13} \mathrm{CO}_{2}$ labelling. Phytochemistry 2007, 68, 2258-2272.

11. Giavalisco, P.; Hummel, J.; Lisec, J.; Inostroza, A.C.; Catchpole, G.; Willmitzer, L. High-resolution direct infusion-based mass spectrometry in combination with whole ${ }^{13} \mathrm{C}$ metabolome isotope labeling allows unambiguous assignment of chemical sum formulas. Anal. Chem. 2008, 80, 9417-9425.

12. Giavalisco, P.; Li, Y.; Matthes, A.; Eckhardt, A.; Hubberten, H.M.; Hesse, H.; Segu, S.; Hummel, J.; Kohl, K.; Willmitzer, L. Elemental formula annotation of polar and lipophilic metabolites using (13) C, (15) $\mathrm{N}$ and (34) $\mathrm{S}$ isotope labelling, in combination with high-resolution mass spectrometry. Plant J. 2011, 68, 364-376.

13. Kalderon, B.; Gopher, A.; Lapidot, A. Metabolic pathways leading to liver glycogen repletion in vivo, studied by GC-MS and NMR. FEBS Lett. 1986, 204, 29-32.

14. Katz, J.; Lee, W.N.; Wals, P.A.; Bergner, E.A. Studies of glycogen synthesis and the Krebs cycle by mass isotopomer analysis with [U- $\left.{ }^{13} \mathrm{C}\right]$ glucose in rats. J. Biol. Chem. 1989, 264, 12994-13004.

15. Katz, J.; Lee, W.N. Application of mass isotopomer analysis for determination of pathways of glycogen synthesis. Am. J. Physiol. 1991, 261, E332-E336.

16. Young, J.D.; Shastri, A.A.; Stephanopoulos, G.; Morgan, J.A. Mapping photoautotrophic metabolism with isotopically nonstationary ${ }^{13} \mathrm{C}$ flux analysis. Metab. Eng. 2011, 13, 656-665.

17. Yuan, J.; Bennett, B.D.; Rabinowitz, J.D. Kinetic flux profiling for quantitation of cellular metabolic fluxes. Nat. Protoc. 2008, 3, 1328-1340.

18. De Koning, W.; van Dam, K. A method for the determination of changes of glycolytic metabolites in yeast on a subsecond time scale using extraction at neutral pH. Anal. Biochem. 1992, 204, 118-123.

19. Villas-Bôas, S.G.; Højer-Pedersen, J.; Åkesson, M.; Smedsgaard, J.; Nielsen, J. Global metabolite analysis of yeast: Evaluation of sample preparation methods. Yeast 2005, 22, 1155-1169.

20. Bolten, C.J.; Kiefer, P.; Letisse, F.; Portais, J.-C.; Wittmann, C. Sampling for metabolome analysis of microorganisms. Anal. Chem. 2007, 79, 3843-3849.

21. Villas-Bôas, S.G.; Bruheim, P. Cold glycerol-saline: The promising quenching solution for accurate intracellular metabolite analysis of microbial cells. Anal. Biochem. 2007, 370, 87-97.

22. Wittmann, C.; Krömer, J.O.; Kiefer, P.; Binz, T.; Heinzle, E. Impact of the cold shock phenomenon on quantification of intracellular metabolites in bacteria. Anal. Biochem. 2004, 327, 135-139. 
23. Bennett, B.D.; Yuan, J.; Kimball, E.H.; Rabinowitz, J.D. Absolute quantitation of intracellular metabolite concentrations by an isotope ratiobased approach. Nat. Protoc. 2008, 3, 1299-1311.

24. Winder, C.L.; Dunn, W.B.; Schuler, S.; Broadhurst, D.; Jarvis, R.; Stephens, G.M.; Goodacre, R. Global metabolic profiling of Escherichia coli cultures: An evaluation of methods for quenching and extraction of intracellular metabolites. Ana. Chem. 2008, 80, 2939-2948.

25. Canelas, A.B.; ten Pierick, A.; Ras, C.; Seifar, R.M.; van Dam, J.C.; van Gulik, W.M.; Heijnen, J.J. Quantitative evaluation of intracellular metabolite extraction techniques for yeast metabolomics. Anal. Chem. 2009, 81, 7379-7389.

26. Geier, F.M.; Want, E.J.; Leroi, A.M.; Bundy, J.G. Cross-platform comparison of Caenorhabditis elegans tissue extraction strategies for comprehensive metabolome coverage. Anal. Chem. 2011, 83, 3730-3736.

27. Dietmair, S.; Timmins, N.E.; Gray, P.P.; Nielsen, L.K.; Krömer, J.O. Towards quantitative metabolomics of mammalian cells: Development of a metabolite extraction protocol. Anal. Biochem. 2010, 404, 155-164.

28. Halket, J.M.; Waterman, D.; Przyborowska, A.M.; Patel, R.K.P.; Fraser, P.D.; Bramley, P.M. Chemical derivatization and mass spectral libraries in metabolic profiling by GC/MS and LC/MS/MS. J. Exp. Bot. 2005, 56, 219-243.

29. Bollinger, J.G.; Thompson, W.; Lai, Y.; Oslund, R.C.; Hallstrand, T.S.; Sadilek, M.; Turecek, F.; Gelb, M.H. Improved sensitivity mass spectrometric detection of eicosanoids by charge reversal derivatization. Anal. Chem. 2010, 82, 6790-6796.

30. Wells, R.J. Recent advances in non-silylation derivatization techniques for gas chromatography. J. Chromatogr. A 1999, 843, 1-18.

31. Fiehn, O.; Kopka, J.; Dormann, P.; Altmann, T.; Trethewey, R.N.; Willmitzer, L. Metabolite profiling for plant functional genomics. Nat. Biotechnol. 2000, 18, 1157-1161.

32. Zhang, B.; Tolstikov, V.; Turnbull, C.; Hicks, L.M.; Fiehn, O. Divergent metabolome and proteome suggest functional independence of dual phloem transport systems in cucurbits. Proc. Natl. Acad. Sci. USA 2010, 107, 13532-13537.

33. Graham, T.L. A rapid, high resolution high performance liquid chromatography profiling procedure for plant and microbial aromatic secondary metabolites. Plant Physiol. 1991, 95, 584-593.

34. Coulier, L.; Bas, R.; Jespersen, S.; Verheij, E.; van der Werf, M.J.; Hankemeier, T. Simultaneous quantitative analysis of metabolites using ion-pair liquid chromatography-electrospray ionization mass spectrometry. Anal. Chem. 2006, 78, 6573-6582.

35. Zhang, B.; Watts, K.M.; Hodge, D.; Kemp, L.M.; Hunstad, D.A.; Hicks, L.M.; Odom, A.R. A second target of the antimalarial and antibacterial agent fosmidomycin revealed by cellular metabolic profiling. Biochemistry 2011, 50, 3570-3577.

36. Magnes, C.; Sinner, F.M.; Regittnig, W.; Pieber, T.R. LC/MS/MS method for quantitative determination of long-chain fatty acyl-CoAs. Anal. Chem. 2005, 77, 2889-2894.

37. Grobe, N.; Zhang, B.; Fisinger, U.; Kutchan, T.M.; Zenk, M.H.; Guengerich, F.P. Mammalian cytochrome P450 enzymes catalyze the phenol-coupling step in endogenous morphine biosynthesis. J. Biol. Chem. 2009, 284, 24425-24431. 
38. Merrill, A.H.; Dennis, E.A.; McDonald, J.G.; Fahy, E. Lipidomics technologies at the end of the first decade and the beginning of the next. Adv. Nutr. 2013, 4, 565-567.

39. Fahy, E.; Sud, M.; Cotter, D.; Subramaniam, S. LIPID MAPS online tools for lipid research. Nucleic Acids Res. 2007, 35, W606-W612.

40. Degenkolbe, T.; Giavalisco, P.; Zuther, E.; Seiwert, B.; Hincha, D.K.; Willmitzer, L. Differential remodeling of the lipidome during cold acclimation in natural accessions of Arabidopsis thaliana. Plant J. 2012, 72, 972-982.

41. Yamada, T.; Uchikata, T.; Sakamoto, S.; Yokoi, Y.; Fukusaki, E.; Bamba, T. Development of a lipid profiling system using reverse-phase liquid chromatography coupled to high-resolution mass spectrometry with rapid polarity switching and an automated lipid identification software. J. Chromatogr. A 2013, 1292, 211-218.

42. Shui, G.; Guan, X.L.; Low, C.P.; Chua, G.H.; Goh, J.S.; Yang, H.; Wenk, M.R. Toward one step analysis of cellular lipidomes using liquid chromatography coupled with mass spectrometry: Application to Saccharomyces cerevisiae and Schizosaccharomyces pombe lipidomics. Mol. Biosyst. 2010, 6, 1008-1017.

43. Bird, S.S.; Marur, V.R.; Sniatynski, M.J.; Greenberg, H.K.; Kristal, B.S. Lipidomics profiling by high-resolution LC-MS and high-energy collisional dissociation fragmentation: Focus on characterization of mitochondrial cardiolipins and monolysocardiolipins. Anal. Chem. 2011, 83, 940-949.

44. Iwasaki, Y.; Goto, M.; Mochizuki, K.; Terayama, E.; Ito, R.; Saito, K.; Sugino, N.; Makino, T.; Nakazawa, H. Development and validation of a hydrophilic interaction chromatography-tandem mass spectrometry for quantification of nicotine and its metabolites in human maternal and cord sera. Biomed. Chromatogr. 2011, 25, 503-510.

45. Lisa, M.; Cifkova, E.; Holcapek, M. Lipidomic profiling of biological tissues using off-line two-dimensional high-performance liquid chromatography-mass spectrometry. J. Chromatogr. A 2011, 1218, 5146-5156.

46. Garcia-Canaveras, J.C.; Donato, M.T.; Castell, J.V.; Lahoz, A. A comprehensive untargeted metabonomic analysis of human steatotic liver tissue by RP and HILIC chromatography coupled to mass spectrometry reveals important metabolic alterations. J. Proteome Res. 2011, 10, $4825-4834$.

47. Donot, F.; Cazals, G.; Gunata, Z.; Egron, D.; Malinge, J.; Strub, C.; Fontana, A.; Schorr-Galindo, S. Analysis of neutral lipids from microalgae by HPLC-ELSD and APCI-MS/MS. J. Chromatogr. B Anal. Technol. Biomed. Life Sci. 2013, 942-943, 98-106.

48. Iwasaki, Y.; Sawada, T.; Hatayama, K.; Ohyagi, A.; Tsukuda, Y.; Namekawa, K.; Ito, R.; Saito, K.; Nakazawa, H. Separation technique for the determination of highly polar metabolites in biological samples. Metabolites 2012, 2, 496-515.

49. Alonso, A.P.; Piasecki, R.J.; Wang, Y.; LaClair, R.W.; Shachar-Hill, Y. Quantifying the labeling and the levels of plant cell wall precursors using ion chromatography tandem mass spectrometry. Plant Physiol. 2010, 153, 915-924. 
50. Iwatani, S.; van Dien, S.; Shimbo, K.; Kubota, K.; Kageyama, N.; Iwahata, D.; Miyano, H.; Hirayama, K.; Usuda, Y.; Shimizu, K.; et al. Determination of metabolic flux changes during fed-batch cultivation from measurements of intracellular amino acids by LC-MS/MS. J. Biotechnol. 2007, 128, 93-111.

51. McNaught, A.D.; Wilkinson, A.; International Union of Pure and Applied Chemistry; Royal Society of Chemistry (Great Britain). In IUPAC Compendium of Chemical Terminology, 2nd ed.; Royal Society of Chemistry: Cambridge, UK, 2000.

52. Pingitore, F.; Tang, Y.; Kruppa, G.H.; Keasling, J.D. Analysis of amino acid isotopomers using FT-ICR MS. Anal. Chem. 2007, 79, 2483-2490.

53. Blank, L.M.; Desphande, R.R.; Schmid, A.; Hayen, H. Analysis of carbon and nitrogen co-metabolism in yeast by ultrahigh-resolution mass spectrometry applying ${ }^{13} \mathrm{C}$ - and ${ }^{15} \mathrm{~N}$-labeled substrates simultaneously. Anal. Bioanal. Chem. 2012, 403, 2291-2305.

54. Lorkiewicz, P.; Higashi, R.M.; Lane, A.N.; Fan, T.W. High information throughput analysis of nucleotides and their isotopically enriched isotopologues by direct-infusion FTICR-MS. Metabolomics 2012, 8, 930-939.

55. Kind, T.; Fiehn, O. Seven Golden Rules for heuristic filtering of molecular formulas obtained by accurate mass spectrometry. BMC Bioinform. 2007, 8, doi:10.1186/1471-2105-8-105.

56. Valkenborg, D.; Mertens, I.; Lemiere, F.; Witters, E.; Burzykowski, T. The isotopic distribution conundrum. Mass Spectrom. Rev. 2012, 31, 96-109.

57. Marshall, A.G.; Blakney, G.T.; Chen, T.; Kaiser, N.K.; McKenna, A.M.; Rodgers, R.P.; Ruddy, B.M.; Xian, F. Mass resolution and mass accuracy: How much is enough? Mass Spectrom. 2013, 2, S0009.

58. Guerrasio, R.; Haberhauer-Troyer, C.; Steiger, M.; Sauer, M.; Mattanovich, D.; Koellensperger, G.; Hann, S. Measurement uncertainty of isotopologue fractions in fluxomics determined via mass spectrometry. Anal. Bioanal. Chem. 2013, 405, 5133-5146.

59. Hall, R.D.; Wishart, D.S.; Roessner, U. Metabolomics and the move towards biology. Metabolomics 2011, 7, 454-456.

60. Caspi, R.; Altman, T.; Dreher, K.; Fulcher, C.A.; Subhraveti, P.; Keseler, I.M.; Kothari, A.; Krummenacker, M.; Latendresse, M.; Mueller, L.A.; et al. The MetaCyc database of metabolic pathways and enzymes and the BioCyc collection of pathway/genome databases. Nucleic Acids Res. 2012, 40, D742-D753.

61. Tohge, T.; Fernie, A. R. Web-based resources for mass-spectrometry-based metabolomics: A user's guide. Phytochemistry 2009, 70, 450-456.

62. Nikolskiy, I.; Mahieu, N.G.; Chen, Y., Jr.; Tautenhahn, R.; Patti, G.J. An untargeted metabolomic workflow to improve structural characterization of metabolites. Anal. Chem. 2013, 85, 7713-7719.

63. Bateman, K.P.; Castro-Perez, J.; Wrona, M.; Shockcor, J.P.; Yu, K.; Oballa, R.; Nicoll-Griffith, D.A. $\mathrm{MS}^{\mathrm{E}}$ with mass defect filtering for in vitro and in vivo metabolite identification. Rapid Commun. Mass Spectrom. 2007, 21, 1485-1496.

64. Wahl, S.A.; Dauner, M.; Wiechert, W. New tools for mass isotopomer data evaluation in ${ }^{13} \mathrm{C}$ flux analysis: Mass isotope correction, data consistency checking, and precursor relationships. Biotechnol. Bioeng. 2004, 85, 259-268. 
65. Eibl, G.; Bernardo, K.; Koal, T.; Ramsay, S. L.; Weinberger, K. M.; Graber, A. Isotope correction of mass spectrometry profiles. Rapid Commun. Mass Spectrom. 2008, 22, 2248-2252.

66. Wu, B.; Zhang, B.; Feng, X.; Rubens, J.R.; Huang, R.; Hicks, L.M.; Pakrasi, H.B.; Tang, Y.J. Alternative isoleucine synthesis pathway in cyanobacterial species. Microbiology 2010, 156, 596-602.

67. McLafferty, F.W.; Tureccek, F. Interpretation of Mass Spectra, 4th ed.; University Science Books: Sausalito, CA, USA, 1993.

68. Moseley, H.N. Correcting for the effects of natural abundance in stable isotope resolved metabolomics experiments involving ultra-high resolution mass spectrometry. BMC Bioinform. 2010, 11, doi:10.1186/1471-2105-11-139.

69. Kind, T.; Tolstikov, V.; Fiehn, O.; Weiss, R.H. A comprehensive urinary metabolomic approach for identifying kidney cancer. Anal. Biochem. 2007, 363, 185-195.

70. Smith, C.A.; Want, E.J.; O’Maille, G.; Abagyan, R.; Siuzdak, G. XCMS: Processing mass spectrometry data for metabolite profiling using nonlinear peak alignment, matching, and identification. Anal. Chem. 2006, 78, 779-787.

71. Pluskal, T.; Castillo, S.; Villar-Briones, A.; Oresic, M. MZmine 2: Modular framework for processing, visualizing, and analyzing mass spectrometry-based molecular profile data. BMC Bioinform. 2010, 11, doi:10.1186/1471-2105-11-395.

72. Katajamaa, M.; Miettinen, J.; Oresic, M. MZmine: Toolbox for processing and visualization of mass spectrometry based molecular profile data. Bioinformatics 2006, 22, 634-636.

73. Smith, C.A.; Maille, G.O.; Want, E.J.; Qin, C.; Trauger, S.A.; Brandon, T.R.; Custodio, D.E.; Abagyan, R.; Siuzdak, G. METLIN: A Metabolite Mass Spectral Database. Ther. Drug Monit. 2005, 27, 747-751

74. Larsen, T.; Taylor, D.L.; Leigh, M.B.; O’Brien, D.M. Stable isotope fingerprinting: A novel method for identifying plant, fungal, or bacterial origins of amino acids. Ecology 2009, 90, 3526-3535.

75. Christiansen, T.; Christensen, B.; Nielsen, J. Metabolic network analysis of Bacillus clausii on minimal and semirich medium using ${ }^{13} \mathrm{C}$-labeled glucose. Metab. Eng. 2002, 4, 159-169.

76. Zhuang, W.Q.; Yi, S.; Feng, X.; Zinder, S.H.; Tang, Y.J.; Alvarez-Cohen, L. Selective utilization of exogenous amino acids by Dehalococcoides ethenogenes strain 195 and the enhancement resulted to dechloronation activity. Appl. Environ. Microbiol. 2011, 77, 7797-7803.

77. Dos Santos, M.M.; Gombert, A.K.; Christensen, B.; Olsson, L.; Nielsen, J. Identification of in vivo enzyme activities in the cometabolism of glucose and acetate by Saccharomyces cerevisiae by using ${ }^{13}$ C-labeled substrates. Eukaryot. Cell 2003, 2, 599-608.

78. Goodson, C.; Roth, R.; Wang, Z.T.; Goodenough, U. Structural correlates of cytoplasmic and chloroplast lipid body synthesis in Chlamydomonas reinhardtii and stimulation of lipid body production with acetate boost. Eukaryot. Cell 2011, 10, 1592-1606.

79. Wyche, K.P.; Blake, R.S.; Willis, K.A.; Monks, P.S.; Ellis, A.M. Differentiation of isobaric compounds using chemical ionization reaction mass spectrometry. Rapid Commun. Mass Spectrom. 2005, 19, 3356-3362. 
80. Fortner, E.C.; Knighton, W.B. Quantitatively resolving mixtures of isobaric compounds using chemical ionization mass spectrometry by modulating the reactant ion composition. Rapid Commun. Mass Spectrom. 2008, 22, 2597-2601.

81. Rodgers, R.; Blumer, E.; Hendrickson, C.; Marshall, A. Stable isotope incorporation triples the upper mass limit for determination of elemental composition by accurate mass measurement. J. Am. Soc. Spectrom. 2000, 11, 835-840.

82. Hegeman, A.D.; Schulte, C.F.; Cui, Q.; Lewis, I.A.; Huttlin, E.L.; Eghbalnia, H.; Harms, A.C.; Ulrich, E.L.; Markley, J.L.; Sussman, M.R. Stable isotope assisted assignment of elemental compositions for metabolomics. Anal. Chem. 2007, 79, 6912-6921.

83. Baran, R.; Bowen, B.P.; Bouskill, N.J.; Brodie, E.L.; Yannone, S.M.; Northen, T.R. Metabolite identification in Synechococcus sp. PCC 7002 using untargeted stable isotope assisted metabolite profiling. Anal. Chem. 2010, 82, 9034-9042.

84. Weber, R.; Selander, E.; Sommer, U.; Viant, M. A stable-isotope mass spectrometry-based metabolic footprinting approach to analyze exudates from phytoplankton. Mar. Drugs 2013, 11, 4158-4175.

85. Hiller, K.; Metallo, C.M.; Kelleher, J.K.; Stephanopoulos, G. Nontargeted elucidation of metabolic pathways using stable-isotope tracers and mass spectrometry. Anal. Chem. 2010, 82, 6621-6628.

86. Creek, D.J.; Chokkathukalam, A.; Jankevics, A.; Burgess, K.E.V.; Breitling, R.; Barrett, M.P. Stable isotope-assisted metabolomics for network-wide metabolic pathway elucidation. Anal. Chem. 2012, 84, 8442-8447.

87. Wu, L.; Mashego, M.R.; van Dam, J.C.; Proell, A.M.; Vinke, J.L.; Ras, C.; van Winden, W.A.; van Gulik, W.M.; Heijnen, J.J. Quantitative analysis of the microbial metabolome by isotope dilution mass spectrometry using uniformly ${ }^{13} \mathrm{C}$-labeled cell extracts as internal standards. Anal. Biochem. 2005, 336, 164-171.

88. Yuan, J.; Fowler, W.U.; Kimball, E.; Lu, W.; Rabinowitz, J.D. Kinetic flux profiling of nitrogen assimilation in Escherichia coli. Nat. Chem. Biol. 2006, 2, 529-530.

89. Cobbold, S.A.; Vaughan, A.M.; Lewis, I.A.; Painter, H.J.; Camargo, N.; Perlman, D.H.; Fishbaugher, M.; Healer, J.; Cowman, A.F.; Kappe, S.H.I.; et al. Kinetic flux profiling elucidates two independent acetyl-CoA biosynthetic pathways in Plasmodium falciparum. J. Biol. Chem. 2013, 288, 36338-36350.

90. Peyraud, R.; Kiefer, P.; Christen, P.; Massou, S.; Portais, J.-C.; Vorholt, J.A. Demonstration of the ethylmalonyl-CoA pathway by using ${ }^{13} \mathrm{C}$ metabolomics. Proc. Natl. Acad. Sci. USA 2009, 106, 4846-4851.

91. Bogorad, I.W.; Lin, T.-S.; Liao, J.C. Synthetic non-oxidative glycolysis enables complete carbon conservation. Nature 2013, 502, 693-697.

92. Butler, J.A.; Mishur, R.J.; Bokov, A.F.; Hakala, K.W.; Weintraub, S.T.; Rea, S.L. Profiling the anaerobic response of C. elegans using GC-MS. PLoS One 2012, 7, e46140.

93. Dalvi, S.; Azetsu, S.; Patrauchan, M.A.; Aktas, D.F.; Fathepure, B.Z. Proteogenomic elucidation of the initial steps in the benzene degradation pathway of a novel halophile, Arhodomonas sp. strain rozel, isolated from a hypersaline environment. Appl. Environ. Microbiol. 2012, 78, 7309-7316. 
94. Hasokawa, M.; Shinohara, M.; Tsugawa, H.; Bamba, T.; Fukusaki, E.; Nishiumi, S.; Nishimura, K.; Yoshida, M.; Ishida, T.; Hirata, K.-I. Identification of biomarkers of stent restenosis with serum metabolomic profiling using gas chromatography/mass spectrometry. Circ. J. 2012, 76, 1864-1873.

95. Trushina, E.; Dutta, T.; Persson, X.-M.T.; Mielke, M.M.; Petersen, R.C. Identification of altered metabolic pathways in plasma and csf in mild cognitive impairment and alzheimer's disease using metabolomics. PLoS One 2013, 8, e63644.

96. Weckwerth, W.; Fiehn, O. Can we discover novel pathways using metabolomic analysis? Curr. Opin. Biotechnol. 2002, 13, 156-160.

97. Vander Heiden, M.G. Targeting cancer metabolism: A therapeutic window opens. Nat. Rev. Drug Discov. 2011, 10, 671-684.

98. Gupta, S.; Kim, J.; Prasad, S.; Aggarwal, B. Regulation of survival, proliferation, invasion, angiogenesis, and metastasis of tumor cells through modulation of inflammatory pathways by nutraceuticals. Cancer Metastasis Rev. 2010, 29, 405-434.

99. Anso, E.; Mullen, A.; Felsher, D.; Mates, J.; DeBerardinis, R.; Chandel, N. Metabolic changes in cancer cells upon suppression of MYC. Cancer Metab. 2013, 1, doi:10.1186/2049-3002-1-7.

100. Nelson, S.J.; Kurhanewicz, J.; Vigneron, D.B.; Larson, P.E.Z.; Harzstark, A.L.; Ferrone, M.; van Criekinge, M.; Chang, J.W.; Bok, R.; Park, I.; et al. Metabolic imaging of patients with prostate cancer using hyperpolarized [1-13C]pyruvate. Sci. Transl. Med. 2013, 5, 198ra108.

101. Luo, Y.; Yoneda, J.; Ohmori, H.; Sasaki, T.; Shimbo, K.; Eto, S.; Kato, Y.; Miyano, H.; Kobayashi, T.; Sasahira, T.; et al. Cancer usurps skeletal muscle as an energy repository. Cancer Res. 2013, 74, 330-340.

102. Dutta, P.; Le, A.; Vander Jagt, D.L.; Tsukamoto, T.; Martinez, G.V.; Dang, C.V.; Gillies, R.J. Evaluation of LDH-A and glutaminase inhibition in vivo by hyperpolarized ${ }^{13} \mathrm{C}$-pyruvate magnetic resonance spectroscopy of tumors. Cancer Res. 2013, 73, 4190-4195.

103. Metallo, C.M.; Vander Heiden, M.G. Understanding metabolic regulation and its influence on cell physiology. Mol. Cell 2013, 49, 388-398.

104. Dauner, M.; Sauer, U. GC-MS analysis of amino acids rapidly provides rich information for isotopomer balancing. Biotechnol. Prog. 2000, 16, 642-649.

105. You, L.; Page, L.; Feng, X.; Berla, B.; Pakrasi, H.B.; Tang, Y.J. Metabolic pathway confirmation and discovery through ${ }^{13} \mathrm{C}$-labeling of proteinogenic amino acids. J. Vis. Exp. 2012, doi:10.3791/3583.

106. Wiechert, W. ${ }^{13} \mathrm{C}$ Metabolic flux analysis. Metab. Eng. 2001, 3, 195-206.

107. Xiong, W.; Liu, L.; Wu, C.; Yang, C.; Wu, Q. ${ }^{13} \mathrm{C}$-Tracer and gas chromatography-mass spectrometry analyses reveal metabolic flux distribution in the oleaginous microalga Chlorella protothecoides. Plant Physiol. 2010, 154, 1001-1011.

108. Hörl, M.; Schnidder, J.; Sauer, U.; Zamboni, N. Non-stationary ${ }^{13}$ C-metabolic flux ratio analysis. Biotechnol. Bioeng. 2013, 110, 3164-3176.

109. Metallo, C.M.; Walther, J.L.; Stephanopoulos, G. Evaluation of ${ }^{13} \mathrm{C}$ isotopic tracers for metabolic flux analysis in mammalian cells. J. Biotechnol. 2009, 144, 167-174.

110. Rühl, M.; Zamboni, N.; Sauer, U. Dynamic flux responses in riboflavin overproducing Bacillus subtilis to increasing glucose limitation in fed-batch culture. Biotechnol. Bioeng. 2010, 105, 795-804. 
111. Wahrheit, J.; Nicolae, A.; Heinzle, E. Eukaryotic metabolism: Measuring compartment fluxes. Biotechnol. J. 2011, 6, 1071-1085.

112. Ahn, W.S.; Antoniewicz, M.R. Towards dynamic metabolic flux analysis in CHO cell cultures. Biotechnol. J. 2012, 7, 61-74.

113. Williams, T.C.R.; Sweetlove, L.J.; Ratcliffe, R.G. Capturing metabolite channeling in metabolic flux phenotypes. Plant Physiol. 2011, 157, 981-984.

114. Heinzle, E.; Matsuda, F.; Miyagawa, H.; Wakasa, K.; Nishioka, T. Estimation of metabolic fluxes, expression levels and metabolite dynamics of a secondary metabolic pathway in potato using label pulse-feeding experiments combined with kinetic network modelling and simulation. Plant J. 2007, 50, 176-187.

115. Hoekstra, R.; Nibourg, G.A.A.; van der Hoeven, T.V.; Ackermans, M.T.; Hakvoort, T.B.M.; van Gulik, T.M.; Lamers, W.H.; Elferink, R.P.O.; Chamuleau, R.A.F.M. The HepaRG cell line is suitable for bioartificial liver application. Int. J. Biochem. Cell Biol. 2011, 43, 1483-1489.

116. Mavri-Damelin, D.; Damelin, L.H.; Eaton, S.; Rees, M.; Selden, C.; Hodgson, H.J.F. Cells for bioartificial liver devices: The human hepatoma-derived cell line C3A produces urea but does not detoxify ammonia. Biotechnol. Bioeng. 2008, 99, 644-651.

117. Nyberg, G.B.; Balcarcel, R.R.; Follstad, B.D.; Stephanopoulos, G.; Wang, D.I.C. Metabolic effects on recombinant interferon- $\gamma$ glycosylation in continuous culture of Chinese hamster ovary cells. Biotechnol. Bioeng. 1999, 62, 336-347.

118. Sengupta, N.; Rose, S.T.; Morgan, J.A. Metabolic flux analysis of CHO cell metabolism in the late non-growth phase. Biotechnol. Bioeng. 2011, 108, 82-92.

119. Ahn, W.; Antoniewicz, M. Metabolic flux analysis of CHO cells at growth and non-growth phases using isotopic tracers and mass spectrometry. Metab. Eng. 2011, 13, 598-609.

120. Stolyar, S.; van Dien, S.; Hillesland, K.L.; Pinel, N.; Lie, T.J.; Leigh, J.A.; Stahl, D.A. Metabolic modeling of a mutualistic microbial community. Mol. Syst. Biol. 2007, 3, doi: 10.1038/msb4100131.

121. De Graaf, A.A.; Maathuis, A.; de Waard, P.; Deutz, N.E.P.; Dijkema, C.; de Vos, W.M.; Venema, K. Profiling human gut bacterial metabolism and its kinetics using [U- $\left.{ }^{13} \mathrm{C}\right]$ glucose and NMR. NMR Biomed. 2010, 23, 2-12.

122. Bombach, P.; Chatzinotas, A.; Neu, T.R.; Kästner, M.; Lueders, T.; Vogt, C. Enrichment and characterization of a sulfate-reducing toluene-degrading microbial consortium by combining in situ microcosms and stable isotope probing techniques. FEMS Microbiol. Ecol. 2010, 71, 237-246.

123. Eisenreich, W.; Dandekar, T.; Heesemann, J.; Goebel, W. Carbon metabolism of intracellular bacterial pathogens and possible links to virulence. Nat. Rev. Microbiol. 2010, 8, 401-412.

124. Fuchs, T.M.; Eisenreich, W.; Kern, T.; Dandekar, T. Towards a systemic understanding of Listeria monocytogenes metabolism during infection. Front. Microbiol. 2012, 3, doi: 10.3389/ fmicb.2012.00023.

125. Götz, A.; Eylert, E.; Eisenreich, W.; Goebel, W. Carbon metabolism of enterobacterial human pathogens growing in epithelial colorectal adenocarcinoma (Caco-2) cells. PLoS One 2010, 5, e10586.

126. Rühl, M.; Hardt, W.D.; Sauer, U. Subpopulation-specific metabolic pathway usage in mixed cultures as revealed by reporter protein-based ${ }^{13} \mathrm{C}$ analysis. Appl. Environ. Microbiol. 2011, 77, 1816-1821. 
127. Galagan, J.E.; Minch, K.; Peterson, M.; Lyubetskaya, A.; Azizi, E.; Sweet, L.; Gomes, A.; Rustad, T.; Dolganov, G.; Glotova, I.; et al. The Mycobacterium tuberculosis regulatory network and hypoxia. Nature 2013, 499, 178-183.

128. Arakawa, K.; Tomita, M. Merging multiple omics datasets in silico: Statistical analyses and data interpretation. In Systems Metabolic Engineering; Alper, H.S., Ed.; Humana Press: New York, NY, USA, 2013; Volume 985, pp. 459-470.

129. Liu, L.; Yang, T.; Ji, J.; Wen, Q.; Morgan, A.; Jin, B.; Chen, G.; Lyell, D.; Stevenson, D.; Ling, X.; et al. Integrating multiple “omics” analyses identifies serological protein biomarkers for preeclampsia. BMC Med. 2013, 11, doi:10.1186/1741-7015-11-236.

130. Zhang, W.; Li, F.; Nie, L. Integrating multiple "omics" analysis for microbial biology: Application and methodologies. Microbiology 2010, 156, 287-301.

131. Yoon, S.; Han, M.-J.; Jeong, H.; Lee, C.; Xia, X.-X.; Lee, D.-H.; Shim, J.; Lee, S.; Oh, T.; Kim, J. Comparative multi-omics systems analysis of Escherichia coli strains B and K-12. Genome Biol. 2012, 13, R37.

132. Villas-Boâs, S.; Moxley, J.; Akesson, M.; Stephanopoulos, G.; Nielsen, J. High-throughput metabolic state analysis: The missing link in integrated functional genomics of yeasts. Biochem. $J$. 2005, 388, 669-677.

133. Gygi, S.P.; Rochon, Y.; Franza, B.R.; Aebersold, R. Correlation between Protein and mRNA Abundance in Yeast. Mol. Cell. Biol. 1999, 19, 1720-1730.

134. Schwab, W. Metabolome diversity: Too few genes, too many metabolites? Phytochemistry 2003, 62, 837-849.

135. Cheng, X.; Hiras, J.; Deng, K.; Bowen, B.; Simmons, B.; Adams, P.; Singer, S.; Northen, T. High throughput nanostructure-initiator mass spectrometry screening of microbial growth conditions for maximal ß-glucosidase production. Front. Microbiol. 2013, 4, doi:10.3389/ fmicb.2013.00365.

136. Reindl, W.; Northen, T.R. Rapid screening of fatty acids using nanostructure-initiator mass spectrometry. Anal. Chem. 2010, 82, 3751-3755.

137. Lane, A.N.; Fan, T.W.; Bousamra, M., 2nd; Higashi, R.M.; Yan, J.; Miller, D.M. Stable isotope-resolved metabolomics (SIRM) in cancer research with clinical application to nonsmall cell lung cancer. OMICS 2011, 15, 173-182.

138. Van der Hooft, J.J.J.; Mihaleva, V.; de Vos, R.C.H.; Bino, R.J.; Vervoort, J. A strategy for fast structural elucidation of metabolites in small volume plant extracts using automated MS-guided LC-MS-SPE-NMR. Magn. Reson. Chem. 2011, 49, S55-S60.

139. Marshall, A.G.; Hendrickson, C.L. High-resolution mass spectrometers. Annu. Rev. Anal. Chem. 2008, 1, 579-599.

140. Antoniewicz, M.R.; Kelleher, J.K.; Stephanopoulos, G. Elementary metabolite units (EMU): A novel framework for modeling isotopic distributions. Metab. Eng. 2007, 9, 68-86.

(C) 2014 by the authors; licensee MDPI, Basel, Switzerland. This article is an open access article distributed under the terms and conditions of the Creative Commons Attribution license (http://creativecommons.org/licenses/by/3.0/). 